\title{
MULTIDRUG RESISTANT Escherichia coli AMONG PATIENTS WITH GASTROINTESTINAL TRACT INFECTIONS SEEKING HEALTH CARE SERVICES AT LAFIA, NIGERIA
}

\author{
${ }^{* 1,2}$ Ya'aba Y., ${ }^{1}$ Mohammed S. B., ${ }^{1}$ Adamu A. S., ${ }^{2}$ Abdullahi S. R., \\ ${ }^{2}$ Salihu G. M. and ${ }^{3}$ Yakubu G. Japhet \\ ${ }^{1}$ Department of Microbiology and Biotechnology, National Institute for Pharmaceutical Research and Development \\ (NIPRD) Abuja, Nigeria. ${ }^{2}$ Department of Microbiology, Federal University of Lafia, Nasarawa State, Nigeria. \\ ${ }^{3}$ Department of Microbiology, Federal University of Technology, Minna, Niger State, Nigeria. \\ * Corresponding author's e-mail: yakyabnig@yahoo.com \\ (Received: 21 ${ }^{\text {st }}$ October, 2020; Accepted: $9^{\text {th }}$ December, 2020)
}

\section{ABSTRACT}

\begin{abstract}
Gastrointestinal tract (GIT) in human plays an important role in providing habitat to various microbial communities including numerous prokaryotic cells numbering over 100 trillion. This study was aimed at accessing the multidrug resistance (MDR) of E. coli among patients with GIT infections seeking health care at Dalhatu Araf Specialist Hospital (DASH), Lafia, Nasarawa state, Nigeria. A total of one hundred and fifty (150) stool samples were collected using sterile sample containers from patients with symptoms of GIT infections in search of medical care in this hospital. The samples collected were processed using standard microbiological methods. Out of the total samples collected, 35.3\% (53/150) revealed the presence of E. coli whereas $64.7 \%$ did not. Extended spectrum beta-lactamases (ESBL) were found in $45.3 \%$ of E. coli obtained in this study, which were further used for the antimicrobial susceptibility test. E. coli were more resistant to ampicillin $(75.51 \%)$, followed by amoxycillin/clavulanic acid $(61.22 \%)$ and were least resistant to imipenems (12.25\%). In conclusion, MDR E. coli producing ESBL are abundant among patients with GIT infections visiting DASH, Lafia. Thus, it is important to determine the genes responsible for this MDR as well as dissemination of adequate information to the masses visiting the hospital for treatment on the possible effects caused by the antibiotics abuse
\end{abstract}

Keywords: Escherichia coli, Multiple-Drug Resistance, Antimicrobial, Gastrointestinal tract, Extended Spectrum Beta-Lactamases, Microbiological methods

\section{INTRODUCTION}

Gastrointestinal tract (GIT) in human plays an important role in providing habitat to various microbial communities including numerous prokaryotic cells numbering over 100 trillion (Sotelo-Coronado et al., 2016). These microbial cells are acquired sometimes after birth; their abundance and variation however, changes over time until a stable microbial community is established (Sotelo-Coronado et al., 2016). The established microbial community remain part of the GIT of humans as normal flora, while some confer health benefits others cause diseases when conditions become favourable (i.e. weakened immune) causing gastroenteritis among many other GIT infections worldwide (Gitahi et al., 2018).

The microorganisms often associated with GIT infections arise through consumption of contaminated food and water (Rahman et al., 2017; Son et al., 2018). In developing countries, there has been a growing concern of the adverse impacts caused by food borne diseases with a record 2 million lives being lost annually and this figure is expected to rise by 2050 if measures are not put in place to curtail this menace (Sell and Dolan, 2018). Among the microorganisms responsible for GIT infections, Escherichia coli has emerged the commonest since it has been frequently isolated from stool of patients across various studies (Gitahi et al., 2018; Sell and Dolan, 2018; Mahmoud et al., 2020).

Escherichia coli are bacteria commonly found in the environment such as air, water and soil (Dandachi et al., 2018; Son et al., 2018). They could also be present in food and inanimate surfaces with abundant presence in the GIT and feces of humans and warm-blooded mammals (Melo et al., 2015; Fratamico et al., 2016; Zhang et al., 2017; Son et al., 2018; Mahmoud et al., 2020). Strains of E. coli are Gram-negative rod-shaped bacteria, which are $0.5 \mu \mathrm{m}$ in diameter and 1.0-3.0 $\mu \mathrm{m}$ in length 
(Zhang et al., 2017). They are non-sporulating, non-fastidious, facultative anaerobes belonging to the Enterobacteriaceae family (Shabana and AlEnazi, 2020). E. coli are normal flora of the GIT of humans and have been regarded as harmless commensals (Onanuga et al., 2019). However, there are various strains of E. coli such as E. coli strain 10418 and 25922 that are now pathogenic due to the possession of virulence genes (Odonkor and Addo, 2018) and have been found responsible for numerous infections including meningitis, hemolytic uremic syndrome, hemorrhagic colitis, septicaemia, thrombotic thrombocytopenic purpura and diarrhoea, which are difficult to treat by most antibiotics (Rahman et al., 2017; Onanuga et al., 2019).

Since the discovery of antibiotics in 1940s, many lives have been saved and lots of diseases have been prevented (Dandachi et al., 2018). This has however changed over the last three decades owing to the resistance put up by infectious bacteria to antimicrobial drugs. This resistance has been widely associated to the indiscriminate use of antibiotics, self-prescription, production of counterfeit drugs and their use in animal husbandry as growth promoters has resulted in the influx of resistance genes into the environment (Son et al., 2018). E. coli plays an important role in the dissemination of these resistant genes through contamination of varying food products globally, both from animals and non-animal origins (Son et al., 2018). The dissemination of these resistant genes in Rplasmids could take place through conjugation, transduction, and transformation, which could be within the same species (i.e. from parent to offspring) known as vertical gene transfer or to other species known as horizontal gene transfer (Kallau et al., 2018; Onyeadi and Agbagwa, 2019). These genes encoding for resistance to one or more class of antibiotics, when inside the genome of a receptive cell, get integrated into the DNA and produce resistance effects through various mechanisms (Onyeadi and Agbagwa, 2019).

The mechanism utilized by E. coli to resist the effects of most prescribed antimicrobial agents is through the production of extended spectrum beta-lactamases (ESBL) (Ruppe et al., 2015). ESBL are hydrolysing enzymes made up of carbapenemases, betalactamases and cephalosporinases, which act on various antimicrobial agents rendering their efforts useless or ineffective (Igwe et al., 2016). Some strains of E. coli possess genes encoding for this ESBL and are very difficult to treat; they are responsible for deaths of patients due to their resistance to first-line medication (Rasheed et al., 2014). Aside ESBL, some strains of E. coli also possess genes coding for fimbrial adhesins (which promote colonization in the GIT) (Son et al., 2018); ampC genes, aerobactin system, K capsule and hemolysin which enhances E. coli resistance to serum killing (Igwe et al., 2016). With the help of these cascade means of resistance, E. coli have been able to evade two or more classes of antibiotics (i.e. tetracycline, penicillin, polymyxin, cephalosporins, macrolides, and sulphonamides among many others) (Kallau et al., 2018) making its inclusion as a multidrug resistant bacterium as characterized by World Health Organization (WHO) (Son et al., 2018). Since E. coli is a major causative agent of GIT infections leading to morbidity and mortality, its abundance in the environment needs to be paid more attention.

As such, this study was aimed at assessing the multidrug resistance of E. coli among patients with GIT infections seeking health care services at Dalhatu Araf Specialist Hospital, Lafia, Nasarawa state.

\section{MATERIALS AND METHODS \\ Study Location}

The study was carried out in Dalhatu Araf Specialist Hospital (DASH) Lafia. Lafia is the state capital of Nasarawa state located in the North central part of Nigeria lying at latitude $8^{\circ} 29^{\prime} 30^{\prime \prime \prime}$ North of the equator and longitude $8^{\circ} 310^{\prime \prime}$ East of Greenwich Meridian (Akwa et al., 2007). The state has a total inhabitant of 330, 712 (NPC, 2006; Akwa et al., 2007). It is presently described that Lafia has a population of about 127, 236 (WPR, 2019).

\section{Ethical Clearance}

The ethical approval for the study was obtained from the Ethical Committees of Dalhatu Araf Specialist Hospital, Lafia, Nasarawa state, Nigeria in accordance with the code of ethics for 
biomedical research involving human subjects. Participants were recruited after they were given associated health talk on the aim and significance of the research.

\section{Sample Collection}

A total of one hundred and fifty (150) stool samples were collected using sterile sample containers from patients with symptoms of gastrointestinal tract (GIT) infections attending medical clinic in Dalhatu Araf Specialist Hospital (DASH) Lafia, Nasarawa state, Nigeria. The samples collected were processed and analysed at Microbiology Laboratory of Federal University of Lafia, Nasarawa state.

\section{Sample Preparation and Isolation of Escherichia coli}

Escherichia coli were isolated from the faecal samples as described by Kallau et al. (2018) and Gitahi et al. (2018) by first suspending $5 \mathrm{~g}$ of the faecal sample into $45 \mathrm{ml}$ of buffered peptone water to make a $10^{-1}$ dilution. The sample was incubated at $37^{\circ} \mathrm{C}$ for $24 \mathrm{hrs}$. After the incubation period, 10-fold serial dilution was done using $0.85 \%$ sterile saline solution and aliquots of $0.1 \mathrm{ml}$ was withdrawn aseptically from well vortexed test tubes labelled $10^{-3}$ and $10^{-4}$ and dispensed into neatly labelled Petri plates respectively. About 15 $\mathrm{ml}$ of molten MacConkey agar (MCA) was dispensed aseptically into the Petri plates containing the aliquots. The MCA plates were mixed gently to obtain an even mixture and were allowed to solidify before incubating them in an inverted position for $24 \mathrm{hrs}$ in the incubator at 37 ${ }^{\circ} \mathrm{C}$. Isolates with characteristics features of E. coli were further isolated, purified and stored in nutrient agar (NA) slant bottles in the refrigerator at $4{ }^{\circ} \mathrm{C}$ for further biochemical characterization, identification and antimicrobial susceptibility test (AST).

\section{Biochemical Identification}

The presumptive microorganisms were subjected to Gram staining including various biochemical tests such as: indole, oxidase, methyl red, Voges Proskauer, motility, triple sugar iron, citrate and sugar utilization tests (galactose, lactose, sucrose and glucose). Reagents used in this study were all obtained from BDH Chemical Ltd, England with strict adherence to manufacturer's instruction during their preparations (Cheesebrough, 2006; Onyeadi and Agbagwa, 2019).

Phenotypic detection of Extended Spectrum Beta-lactamases (ESBL) Production

Production of extended spectrum betalactamases (ESBL) by strains of $E$. coli was assessed utilizing combination of antibiotics diffusion methods. The strains were standardized to turbidity of $0.5 \mathrm{McF}$ arland standards before inoculation on the surface of solidified Muller Hinton agar (MHA) using a sterile swab stick. Standard antimicrobial discs of amoxicillinclavulanate $(30 \mu \mathrm{g})$, cefotaxime $(30 \mu \mathrm{g})$ and ceftazidime $(30 \mu \mathrm{g})$ were placed aseptically $20 \mathrm{~mm}$ away from each other using forceps. The MHA plates were allowed to stand for 30 mins to allow pre-diffusion before it was then incubated for 24 hours at $37{ }^{\circ} \mathrm{C}$. The zones of inhibitions were measured using metre rule and evaluated. The isolates whose zone of inhibition of both cefotaxime and ceftazidime were greater than zones of inhibition of amoxicillin-clavulanate were taken as positive producers of ESBL (Onanuga et al., 2019; Mahmoud et al., 2020).

\section{Antibiotic Susceptibility Tests}

The antibiograms of the test isolates were carried out following the methods documented by Clinical and Laboratory Standard Institute (Adeyemi et al., 2015). The test isolates were first adjusted to $10^{5}$ cells equivalent to turbidity of 0.5 McFarland standards before using a sterile swab stick to surface inoculate onto Muller Hinton agar (MHA). The plates were then allowed to stand for 30 minutes to ensure pre-diffusion of test isolates. The standard antibiotics discs were placed aseptically on surfaces of inoculated MHA using sterile forceps and allowed to pre-diffuse for 15 mins before incubating it in the incubator for 18 hrs at $37{ }^{\circ} \mathrm{C}$. After incubation period, the MHA plates were brought out and readings of zone of inhibition were taken in millimeter ( $\mathrm{mm}$ ) using the meter rule. The antibiotic discs used include: ceftazidime $(30 \mu \mathrm{g})$, imipenem $(30 \mu \mathrm{g})$, ceftriaxone $(30 \mu \mathrm{g})$, gentamycin $(10 \mu \mathrm{g})$, ampicillin $(30 \mu \mathrm{g})$, streptomycin $(30 \mu \mathrm{g})$, cefotaxime $(30 \mu \mathrm{g})$, amoxycillin/clavulanic acid $(30 \mu \mathrm{g})$, ciprofloxacin $(5 \mu \mathrm{g})$, and sulphamethoxazole/trimethoprim (25 $\mu \mathrm{g})$. 


\section{Data Analysis}

The data were analysed using SPSS (version 20) statistical software.

\section{RESULT}

\section{Prevalence of Escherichia coli in Stool Sample}

Out of one hundred and fifty (150) stool samples collected from patients with symptoms of gastrointestinal tract infections at Dalhatu Araf Specialist Hospital, Lafia, 53 (35.3\%) of the samples reported the presence of E. coli, whereas $97(64.7 \%)$ of the samples did not detect presence of E. coli.

\section{Escherichia coli Producing ESBL}

Out of 53 samples screened for E. coli producing ESBL, $45.3 \%$ were reported to be positive, which were further used for the antimicrobial susceptibility test.

Percentage Resistance and Susceptibility of E. coli to Antibiotics

Antibiotic resistance and susceptibility of E. coli isolated from the stools of patients is shown in table 1 . The result showed that E. coli were more resistant to ampicillin (75.51\%), followed by amoxycillin/clavulanic acid (61.22\%) and was least resistant to imipenem $(12.25 \%)$, other antibiotics were also sensitive against $E$. coli as most of them showed percentage of susceptibility above $40 \%$ with the exception of ampicillin $(24.49 \%)$ and amoxycillin/clavulanic (38.78\%).

\section{Antibiotics Resistance Phenotypes of Escherichia coli from Stool of Patients}

Thirty-four (34) different pattern of resistance was observed with ceftazidime (CAZ), amoxycillin/clavulanic acid (AMC), sulphamethoxazole/trimethoprim (SXT), ciprofloxacin (CIP), streptomycin (STR), cefotaxime (CTX), and gentamycin (GM). Table 2 shows that 49 out of 53 isolates recorded resistance to two or more antibiotics. More isolates (18) were found to be resistant to four (4) different antibiotics followed by 12 isolates, which were resistant to 3 different antibiotics. However, 6 isolates were recorded to be widest since they were recorded to resist 8 different antibiotics.

Table 1: Antibiotics Resistance and Susceptibility of E. coli from Stool of Patients

\begin{tabular}{lcccccccccc}
\hline Reaction & $\begin{array}{c}\text { CRO } \\
(\%)\end{array}$ & $\begin{array}{c}\text { AMC } \\
(\%)\end{array}$ & $\begin{array}{c}\text { IPM } \\
(\%)\end{array}$ & $\begin{array}{c}\text { CIP } \\
(\%)\end{array}$ & $\begin{array}{c}\text { CTX } \\
(\%)\end{array}$ & $\begin{array}{c}\text { STR } \\
(\%)\end{array}$ & $\begin{array}{c}\text { AMP } \\
(\%)\end{array}$ & $\begin{array}{c}\text { SXT } \\
(\%)\end{array}$ & $\begin{array}{c}\text { CAZ } \\
(\%)\end{array}$ & $\begin{array}{c}\text { GM } \\
(\%)\end{array}$ \\
\hline \multirow{2}{*}{$\mathrm{R}$} & 17 & 30 & 6 & 12 & 18 & 19 & 37 & 25 & 16 & 13 \\
& $(34.69)$ & $(61.22)$ & $(12.25)$ & $(24.49)$ & $(36.73)$ & $(38.78)$ & $(75.51)$ & $(51.02)$ & $(32.65)$ & $(26.53)$ \\
& 32 & 19 & 43 & 37 & 32 & 30 & 12 & 24 & 33 & 36 \\
$\mathrm{~S}$ & $(65.31)$ & $(38.78)$ & $(87.76)$ & $(75.51)$ & $(65.31)$ & $(61.22)$ & $(24.49)$ & $(48.98)$ & $(67.35)$ & $(73.47)$ \\
Total & 49 & 49 & 49 & 49 & 49 & 49 & 49 & 49 & 49 & 49 \\
\hline
\end{tabular}

Abbreviations: $\mathrm{CRO}(30 \mu \mathrm{g})=$ Ceftriaxone, $\operatorname{AMC}(30 \mu \mathrm{g})=$ Amoxycillin/Clavulanic acid, IPM $(30 \mu \mathrm{g})=$ Imipenem, CIP $(5 \mu \mathrm{g})=$ Ciprofloxacin, CTX $(30 \mu \mathrm{g})=$ Cefotaxime, STR $(30 \mu \mathrm{g})=$ Streptomycin, SXT $(25 \mu \mathrm{g})=$ Sulphamethoxazole/Trimethoprim, AMP $(30 \mu \mathrm{g})=$ Ampicillin, CAZ $(30 \mu \mathrm{g})=$ Ceftazidime, and GM $(30 \mu \mathrm{g})=$ Gentamycin, $\mathrm{R}=$ Resistant, $\mathrm{S}=$ Susceptible 
Table 2: Antibiotic Resistance Phenotypes of E. colifrom Stool of Patients

\begin{tabular}{ll}
\hline Phenotypic resistance profile & No. of E. coli isolates (\%) \\
\hline CRO, CTX & $1(1.90)$ \\
GM, AMP, CRO & $1(1.90)$ \\
IMP, CTX, SXT & $1(1.90)$ \\
CIP, AMP, SXT, CRO & $2(3.77)$ \\
STR, CRO, CAZ & $1(1.90)$ \\
GM, AMP, STR & $1(1.90)$ \\
GM, CRO, SXT, STR, & $1(1.90)$ \\
AMC, AMP, SXT, STR, & $1(1.90)$ \\
AMC, AMP, CTX, CIP, & $2(3.77)$ \\
CIP, AMP, CRO, CTX & $1(1.90)$ \\
GM, AMP, SXT, IMP & $1(1.90)$ \\
CRO, SXT, IMP & $1(1.90)$ \\
AMC, CRO, STR & $1(1.90)$ \\
CTX, SXT, GM & $1(1.90)$ \\
CTX, STR, CRO & $1(1.90)$ \\
STR, AMP, CRO, SXT & $1(1.90)$ \\
AMC, AMP, STR, IMP, & $1(1.90)$ \\
GM, AMP, CTX, SXT, & $2(3.77)$ \\
AMC, AMP, GM, SXT, & $1(1.90)$ \\
AMC, AMP, CAZ, SXT & $1(1.90)$ \\
CIP, SXT, STR, CAZ & $1(1.90)$ \\
STR, AMP, CRO, CAZ & $1(1.90)$ \\
STR, AMC, GM, CTX & $1(1.90)$ \\
STR, AMP, SXT, CTX & $1(1.90)$ \\
AMC, AMP, CIP, CAZ, CRO & $1(1.90)$ \\
AMC, AMP, STR, SXT, CAZ & $1(1.90)$ \\
AMC, AMP, CAZ, SXT, CRO, CIP, STR & $6(11.32)$ \\
CAZ, AMP, CRO & $2(3.77)$ \\
AMP, STR, AMC & $1(1.90)$ \\
AMC, GM, AMP & $1(1.90)$ \\
AMC, AMP, STR, CRO, SXT & $1(1.90)$ \\
AMC, AMP, GM, CTX, SXT & $3(5.66)$ \\
AMC, AMP, CIP, CRO, IMP & $2(3.77)$ \\
AMC, AMP & $4(7.55)$ \\
\hline
\end{tabular}

Abbreviations: $\mathrm{CRO}=$ Ceftriaxone, $\mathrm{AMC}=$ Amoxycillin $/$ Clavulanic acid, $\mathrm{IMP}=$ Imipenem, $\mathrm{CIP}=$ Ciprofloxacin, CTX = Cefotaxime, STR $=$ Streptomycin, SXT $=$ Sulphamethoxazole/Trimethoprim, $\mathrm{AMP}=$ Ampicillin, $\mathrm{CAZ}=$ Ceftazidime, and $\mathrm{GM}=$ Gentamycin.

\section{DISCUSSION}

Resistance to antibiotic has become a threat to public health and the world at large. Many lives have been lost and much resources spent in order to tackle this menace. However, the indiscriminate usage of antibiotics, over/under dose, selfprescription, untreated pharmaceutical effluent, and excessive use of antibiotics in animal husbandry as growth promoters among many other conditions have led to widespread of resistant gene in the environment. Viable bacterial species pick up these resistant genes and pass it on through horizontal gene transfer (different species) or vertical gene transfer (to offspring). E. coli has been reported to be abundant in environment with poor sanitary condition especially in developing countries. The abundant presence of E. coli has made them to be an important vehicle for the dissemination of resistant genes as such, GIT diseases in both humans and animals, as a result of E. coli, becomes difficult to treat with conventional antibiotics (Rasheed et al., 2014). 
In this study, prevalence of E. coli was reported to be $53(35.3 \%)$ from a total of 150 stool samples screened. This prevalence rate $(35.3 \%)$ is quite similar to that of Rahman et al. (2017), which reported a prevalence rate of $37.87 \%$ from milk, chicken meat and beef. However, the prevalence in this study is far above $6.40 \%$ reported by Oluwayinka and Oladayo (2017), who isolated their microorganisms from wound swab. A high prevalence $(85.4 \%)$ of E. coli was however reported by Kallau et al. (2018) from feces of pigs. This high prevalence reported by Kallau et al. (2018) could be as a result of the sanitary practice, which is mostly low in pig farming as a low prevalence $(6.40 \%)$ was obtained from wound swab as reported by Oluwayinka and Oladayo (2017). This indicates that E. coli are abundant in environment with poor sanitary condition. The prevalence of E. coli recorded in this study could be related to misuse of antibiotics as well as standard of living of people since the route of transmission is usually faecal-oral-route.

The antibiograms profile of isolates of E. coli in this study is of concern, particularly with ampicillin (AMP) (75.51\%), amoxycillin /clavulanic acid (AMC) (61.22\%), and sulphamethoxazole/trimethoprim (SXT) $(51.02 \%)$ which all showed resistance above $50 \%$. The above-mentioned antibiotics are commonly used by clinicians in treatment of bacterial infections. If E. coli continues to build resistance to these antibiotics, they will be completely resistant and become a major threat to public health.

Resistance to multiple antibiotics was seen in this study. All the isolates of E. coli $(100 \%)$ were resistant to two or more antibiotics. The rate of multidrug resistant E. coli emerging among patients with GIT infections is alarming and if not properly checked can escalate to something difficult to control in the nearest future. In the antibiogram phenotypic profile in table 2, six isolates were recorded to be resistant to eight (8) out of the ten (10) antibiotics tested. This result is similar to the one obtained by Igwe et al. (2016), which reported resistance by strains of E. coli to multiple antibiotics ranging from 5 to 13 . Likewise, report documented by Son et al. (2018), where strains of E. coli exhibited resistant to various antibiotics ranging from 3 to 9. Various studies including Kallau et al. (2018), Rasheed et al. (2014), Anusha et al. (2015), Melo et al. (2015), Oluwayinka and Oladayo (2017), Zhang et al. (2017), Onyeadi and Agbagwa (2019), Onanuga et al. (2019) and Shabana and Al-Enazi (2020) all recorded resistance by strains of E. coli to multiple antibiotics ranging from 2 to 13 . As such, it is important that more attention is paid to ailments such as GIT infections caused by E. coli to proffer effective treatment regiments so as to avoid morbidity and mortality of patients.

\section{RECOMMENDATIONS}

With the phenotypic antibiogram pattern of strains of E. coli obtained in this study, it is important to determine the genes responsible for this multiple-drug resistance as well as dissemination of adequate information to the masses visiting the hospital for treatment on the effects caused by abuse of antibiotics.

\section{CONFLICT OF INTEREST}

The authors declare no conflict of interest.

\section{REFERENCES}

Adeyemi, F.M., Ako-Nai, K.A., Adejuyigbe, E., Ebhodaghe, B.I., Osho, P.O., Oyeniyi, T.T. and Kassim, O.O. 2015. Molecular characterization and antibiotic resistance profiles of bacterial isolates cultured from HIV seropositive patients. Archives of ClinicalMicrobiology, 6(1,2):1-11.

Akwa, V.L., Bimbol, N.L., Samaila, K.L. and Macus, N.D. 2007. Geography perspective of Nassarawa state. Onaivi Printing and Publishing Company, Keffi, Nigeria. $1^{\text {st }}$ ed pp 3-5.

Anusha, S.U., Sundar, S.K. and Rajan, S. 2015. RAPD pattern, virulence nature and plasmid profile of MDR uropathogenic Escherichia coli. Advances in Applied Science Research, 6(7): 145-151.

Cheesebrough, M. 2006. Medical Laboratory Manual for Tropical Countries. Cambridge: Cambridge University Press, $p$ p 49-97.

Dandachi, I., Chaddad, A., Hanna, J., Matta, J. and Daoud, Z. 2018. Understanding the epidemiology of multidrug resistant 
Gram-negative bacilli in the Middle East using a one health approach. Frontiers in Microbiology, 10: 1941.

Fratamico, P.M., DebRoy, C., Liu, Y., Needleman, D.S., Baranzoni, G.M. and Feng, P. 2016. Advances in molecular serotyping and subtyping of Escherichia coli. Frontiers in Microbiology, 7:644.

Gitahi, N.J., Gathura, P B., Gicheru, M.M., Githinji, T.W. and Nordin, A. 2018. Multidrug resistant Escherichia coli isolated from asymptomatic school going children in Kibera slum, Kenya. African Journal of Bacteriology Research, 10(5): 70-77.

Igwe, J.C., Olayinka, B.O., Ehnimidu, J.O. and Onaolapo, J.A. 2016. Virulent characteristics of multidrug resistant $E$. coli from Zaria. Nigeria Clinical Microbiology, 5: 6. Available from: https://doi: 10.4172/2327-5073.1000268 (Accessed $7^{\text {th }}$ Sept. 2020).

Kallau, N.H.G., Wibawan, I.W.T., Lukman, D.W.D. and Sudarwanto, M.B. 2018. Detection of multidrug resistant (MDR) Escherichia coli and the gene prevalence at a pig farm in Kupang, Indonesia. Journal of Advanced Veterinary and Animal Research, 5(4):388-396.

Mahmoud, A.T., Salim, M.T., Ibrahem, A.A., Gabr, A. and Halby, H.M. 2020. Multiple drug resistance patterns in various phylogenetic groups of hospital-acquired uropathogenic E. coli isolated from cancer patients. Antibiotics, 9: 108.

Melo, D.B., Menezes, A.P.O., Reis, J.N. and Guimarães, A.G. 2015. Antimicrobial resistance and genetic diversity of Escherichia coli isolated from humans and foods. Brazilian Journal of Microbiology, 46(4): 1165-1170.

(NPC (2006). National Population Census $\mathrm{R}$ e $\mathrm{trie}$ e $\mathrm{from}$ : "https://en.wikipedia.org/w/index.php? title=Lafia\& oldid $=917958901$ "Centre for Disease Control and Prevention. Accessed $7^{\text {th }}$ Sept. 2020.

Odonkor, S.T. and Addo, K.K. 2018. Prevalence of Multidrug-Resistant Escherichia coli isolated from drinking water sources. International Journal of Microbiology, Article ID 7204013.
Oluwayinka, A.P. and Oladayo, A.C. 2017. plasmid profile of multidrug resistant bacteria isolated from wound swabs from hospital patients in Akure, Nigeria. Asian Journal of Medicine and Health, 2(3): 1-13.

Onanuga, A., Mahindroo, J., Singh, S. and Taneja, N. 2019. Phenotypic and molecular characterization of antimicrobial resistant Escherichia coli from urinary tract infections in Port-Harcourt, Nigeria. Pan African Medical Journal, 34: 144.

Onyeadi, D.J. and Agbagwa, O.E. 2019. Plasmid curing in multidrug resistant hospital and community uropathogenic Escherichia coli. Journal of Applied Science Environmental Management, 23(1):29-34.

Rahman, M.A., Rahman, A.K.M.A., Islam, M.A. and Alam, M.M. 2017. Antimicrobial resistance of Escherichia coli isolated from milk, beef and chicken meat in Bangladesh. Bangladesh Journal of Veterinary Medicine, 15(2): 141-146.

Rasheed, M.U., Thajuddin, N., Ahamed, P., Teklemariam, Z. and Jamil, K. 2014. Antimicrobial drug resistance in strains of Escherichia coli isolated from food sources. Journal of the Institute of Tropical Medicine, Sao Paulo, 56(4):341-346.

Ruppe, E., Woerther, P. L. and Barbier, F. 2015. Mechanisms of antimicrobial resistance in gram-negative bacilli. Annals of Intensive Care, 5: 21. Available from: https://doi: 10.1186/s13613-015-0061-0 (Accessed $8^{\text {th }}$ Sept. 2020).

Sell, J. and Dolan, B. 2018. Common gastrointestinal infections. Primary Care: Clinics in Office Practice, 45: 519-532.

Shabana, I.I. and Al-Enazi, A.T. 2020. Investigation of plasmid-mediated resistance in E. coli isolated from healthy and diarrheic sheep and goats. Saudi Journal of Biological Sciences, 27: 788-796.

Son, S.H., Seo, K.W., Kim, Y.B., Jeon, H.Y., Noh, E.B. and Lee, Y.J. 2018. Molecular characterization of Multidrug-Resistant Escherichia coli isolates from edible offal in Korea. Journal of Food Protection, 82(7): 1183-1190.

Sotelo-Coronado, J.I., Flores-Aréchiga, A., LlacaDíaz, J., Pérez-Chávez, F., LozanoQuintanilla, S. and Casillas-Vega, N. 2016. 
Review: Associated microorganisms to gastrointestinal infections. Rev Latinoam Patol Clin MedLab, 63(4): 206-210.

World Population Review (WPR). 2019: Population of Cities in Nigeria. Retrieved from: https://worldpopulationreview.com/cou ntries/nigeriapopulation/cities/.Tuesday, 15/10/ 2019:21:18.
Zhang, H., Zhao, X., Wang, X. and Chang, W. 2017. Prevalence and antimicrobial resistance profiles of Escherichia coli isolated from free-range pigs. Journal of Infection in Developing Countries, 11(8): 652655. 